\title{
НОВАЯ БИОЛЮМИНЕСЦЕНТНАЯ СИСТЕМА ГРИБОВ: ПЕРСПЕКТИВЫ ИСПОЛЬЗОВАНИЯ В МЕДИЦИНСКИХ ИССЛЕДОВАНИЯХ
}

\author{
3. М. Осипова, А. С. Щеглов $\bowtie$, И. В. Ямпольский
}

Отдел биомолекулярной химии,

Институт биоорганической химии им. академиков М. М. Шемякина и Ю. А. Овчинникова РАН, Москва

\begin{abstract}
Биолюминесценция - это химическое окисление небольшой молекулы люциферина кислородом воздуха под действием белка люциферазы, которое сопровождается эмиссией кванта света в видимой области спектра. На основе этой реакции были разработаны различные методы биолюминесцентного имиджинга - получения изображения в живом организме. Они активно используются в медицинских исследованиях. Однако недостатком существующих люминесцентных систем является необходимость добавления люциферина извне перед каждым экспериментом. В настоящей работе обсуждается возможность разработки автономной люминесцентной системы эукариот на основе биолюминесцентной системы высших грибов.
\end{abstract}

Ключевые слова: биолюминесценция, биоимиджинг, опухолевые модели in vivo, фотодинамическая терапия

Финансирование: работа поддержана Министерством образования и науки РФ, идентисикатор проекта RFMEFI61317X0062.

$\bowtie$ Для корреспонденции: Щеглов Александр Сергеевич

ул. Миклухо-Маклая, д. 16/10, г. Москва, 117997; jukart@mail.ru

Статья получена: 15.12.2017 Статья принята к печати: 27.12.2017

DOI: $10.24075 /$ vrgmu.2018.004

\section{A BIOLUMINESCENT SYSTEM OF FUNGI: PROSPECTS FOR APPLICATION IN MEDICAL RESEARCH}

Osipova ZM, Shcheglov AS $\bowtie$, Yampolsky IV

Department of Biomolecular Chemistry,

Shemyakin-Ovchinnikov Institute of Bioorganic Chemistry of the Russian Academy of Sciences, Moscow, Russia

Bioluminescence is chemical oxidation of a small luciferin molecule by air catalyzed by luciferase and accompanied by the emission of photons in the visible spectrum. This reaction is used in bioluminescent bioimaging, the method for the visualization of organism's interior. Bioimaging is a popular tool used in medical research. However, it has an unfortunate drawback: it requires introduction of external luciferin to the system before every experiment. In this work we discuss a possibility of developing an autonomous luminescent system in eukaryotes based on the bioluminescent system of higher fungi.

Keywords: bioluminescence, bioimaging, tumor models in vivo, photodynamic therapy

Funding: this work was supported by the Ministry of Education and Science of the Russian Federation, Project ID RFMEFI61317X0062.

Correspondence should be addressed: Alexander Shcheglov

ul. Miklukho-Maklaya, d. 16/10, Moscow, Russia, 117997; jukart@mail.ru

Received: 15.12.2017 Accepted: 27.12.2017

DOI: $10.24075 / \mathrm{brsmu} .2018 .004$

Среди живых существ встречаются тысячи видов, способных к излучению света. Такие виды называются биолюминесцентными. Большинство из них обитает на глубине морей и океанов, однако и на поверхности распространены светящиеся насекомые, черви, грибы. В процессе биолюминесценции происходит химическое окисление небольшой молекулы люциферина кислородом воздуха под действием белка люциферазы: квант света в видимой области спектра является одним из продуктов этой реакции. На ее основе были разработаны различные методы биолюминесцентного имиджинга (получения изображения в живом организме), нашедшие свое применение в области медицинских исследований, в особенности при изучении опухолевых заболеваний, и разработке лекарственных препаратов. В последние годы биоимиджинговые технологии становятся все более популярными ввиду беспрецедентной чувствительности при получении изображения в живом организме (вплоть до нескольких отдельных клеток).
Среди природного разнообразия уникальных пар «люциферин-люцифераза» (по разным оценкам, их около 40 [1]) реальное применение пока находят только хорошо изученные биолюминесцентные системы, а именно: система на основе D-люциферина светляка, бактериальная и целентеразиновая системы. При этом каждому люциферину соответствует набор "комплементарных» люцифераз из разных организмов. Например, для D люциферина известны около 30 природных люцифераз, для целентеразина - около 15 люцифераз и 8 фотопротеинов (стабильных субстрат-белковых комплексов) [2]. Как только становится известна аминокислотная последовательность природной люциферазы, появляется принципиальная возможность поместить кодирующий ее ген в другой организм и таким образом добиться экспрессии данного белка в изучаемых клетках. При добавлении люциферина извне нужные клетки будут люминесцировать, что и можно будет зафиксировать как аналитический сигнал. Помимо биоимиджинга 
тканей и клеток возможен имиджинг отдельных органелл и даже межклеточных/межбелковых взаимодействий. А при условии одновременного использования разных люциферинов, их функциональных аналогов и разных люцифераз (как природного типа, так и мутантных) возможности имиджинга возрастают многократно - становится реальным проведение мультицветовых исследований [3-6].

\section{Биолюминесцентные методы в медицине}

Самое широкое распространение в медицинских исследованиях получила биолюминесцентная реакция D люциферина светляка. Ее особенность в том, что она проходит только в присутствии кофрактора аденозинтрифоосфата (АТФ). Поэтому получение биолюминесцентного сигнала возможно только в условиях наличия АТФ, что позволяет однозначно определять концентрацию АТФ с помощью биолюминесценции. Поскольку в клетках АТФ работает как универсальный энергоноситель, то измерение его концентрации помогает оценить их метаболический потенциал, а также цитотоксичность различных препаратов или их влияние на пролиферацию клеток [7]. В то же время для работы бактериальной биолюминесцентной системы необходимо наличие таких кофакторов, как флавиномононуклеотид (ФМН) и никотинамидадениндинуклеотид (НАДН). Эта особенность используется для разработки аналитических методов биолюминесцентного определения НАД(Ф) Н, дегидрогеназ и, соответственно, различных метаболитов, окисление которых сопровождается восстановлением НАД+ до НАДН: малата, сорбита, этанола и т. д. Совместное применение светляковой и бактериальной люминесцентных систем позволяет создавать метаболические карты опухолевых тканей и находить возможные подходы к лечению опухолей [8-10].

Безусловно, наиболее полную картину развития ракового заболевания позволяют получить опухолевые модели in vivo. Следить за метастазированием клеток и ангиогенезом, а также ответом на лечение в глубоких тканях можно с использованием имиджинговых технологий, таких как МРТ, ПЭТ, радиография и др. По сравнению с традиционными методами биолюминесцентный имиджинг гораздо более предпочителен ввиду высокой чувствительности. Возможно даже получение трехмерных изображений [11].

Для неинвазивного имиджинга опухолей используют, как правило, люциферазы Photinus pyralis, Pyrophorus plagiophtalamus (совместно c D-люциферином) и люци- феразы Renilla reniformis и Gaussia princeps (совместно с целентеразином). В последнее время становится популярным применение небольшой люциферазы NanoLuc, которая работает с синтетическим люциферином фуримазином [12]. Помимо люцифераз также часто используют конъюгаты люцифераз с флуоресцентными белками и квантовыми точками с целью смещения сигнала в более красную область спектра по BRET-механизму, что актуально для получения изображений в глубоких тканях $[13,14]$.

Еще одним направлением применения биолюминесценции в исследованиях рака является фотодинамическая терапия опухолей с помощью квантовых точек. Фотосенсибилизатор, обладающий значительным цитотоксическим эффектом на опухолевые клетки, находящиеся в глубоких тканях, может быть эффективно активирован светом от люциферазы по BRET-механизму [15, 16].

\section{Люминесцентная система высших грибов - новая альтернатива}

Существенным недостатком люминесцентных систем, применяемых для биоимиджинга в опухолевых исследованиях, является необходимость добавления люциферина извне перед каждым экспериментом. Единственная доступная на данный момент автономная люминесцентная система бактерий, состоящая из оперона luxCDABE, не может широко применяться из-за высокой токсичности. Изначально достаточно долго не удавалось провести экспрессию бактериальной системы в клетках эукариот, однако после полномасштабной перестройки бактериального оперона биолюминесценция в клетках дрожжей и человека стала возможной, но только при условии добавления люциферина извне [17]. И лишь в 2010 г. после дополнительной реорганизации генов в опероне впервые были получены автономно люминесцентные клетки человека [18].

На данный момент бактериальная люминесцентная система все еще непопулярна для применения в эукариотических клетках. Тем более, что, скорее всего, для ее переноса в другой организм потребуются такие же обширные манипуляции с опероном, которые были проделаны в случае первичной оптимизации IuхCDABE, а именно: изменение регуляторных последовательностей, последовательности генов в опероне и создание дополнительных линкерных участков. Поэтому задача по разработке автономно люминесцентной системы по-прежнему актуальна.

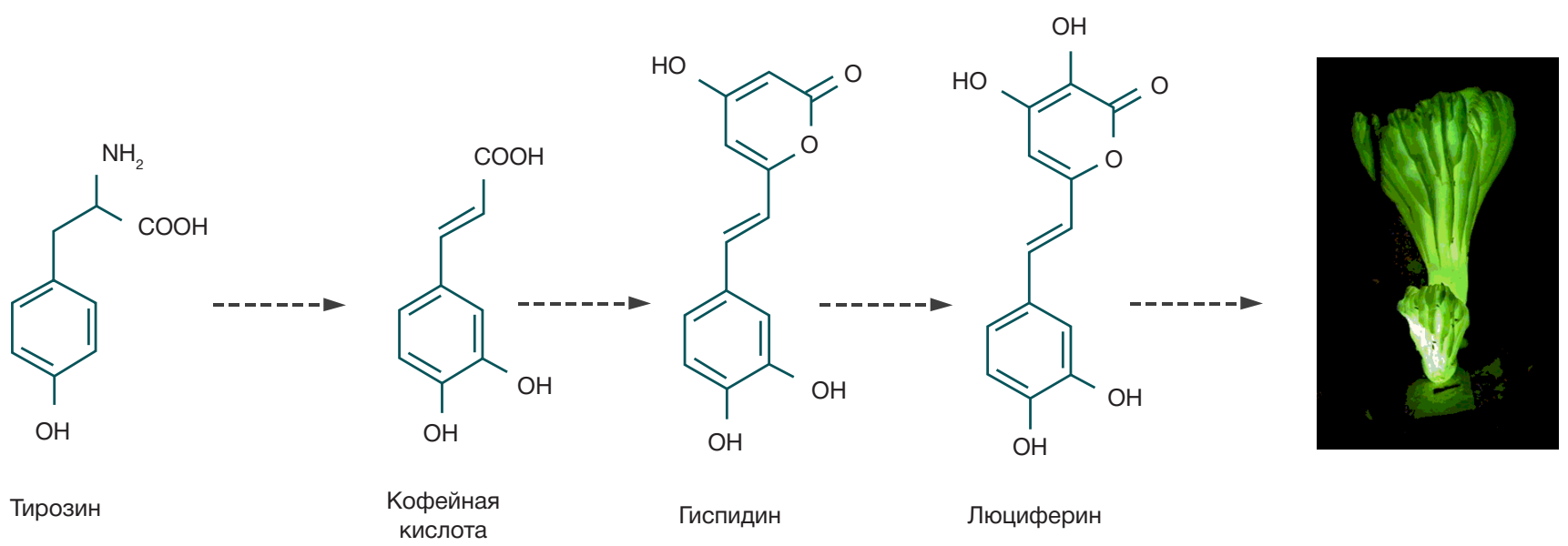

Схема биосинтеза люциферина светящихся высших грибов 
Для применяемых на данный момент люциферинов (D-люциферин, целентеразин) задача пока выглядит нерешаемой, поскольку нет четкого представления о путях биосинтеза этих молекул в живом организме. В то же время относительно недавно стала известная структура люциферина высших грибов - 3-гидроксигиспидина [19], и был подробно изучен механизм его билюминесценции [20]. Биосинтетическим прекурсом люциферина в грибах является кофейная кислота. Из нее люциферин получается в две стадии: сначала из производных кофейной кислоть каффеоила-СоА и малонила-СоА под действием поликетидсинтазы образуется гиспидин [21], который затем в светящихся грибах под действием гидроксилазы превращается в люциферин (рисунок).

Кофейная кислота - это широко распространенный вторичный метаболит растений. Перенос генов белков, ответственных за синтез и свечение люциферина, из грибов в другой эукариотический организм (в частности, в клетки растений) представляется гораздо более реалистичной задачей, чем работа с прокариотическими генами бактерий. Однако, на наш взгляд, существует также и принципиальная возможность получения на основе генов из люминесцентной системы грибов автономно светящихся клеток не только растений, но и других организмов, например дрожжей и млекопитающих. Ферменты, отвечающие за биосинтез кофейной кислоты из L-тирозина в две стадии, известны (PAL фенилаланинаммиаклиаза и C4H циннамат-4-монооксигеназа), как и кодирующие их гены (sam8 и sam5 соответственно) [22]. Присоединение их к кластеру генов люминесцентной системы грибов позволит создать первую полноценную автономную биолюминесцентную систему, подходящую для биомиджинга в эукариотических организмах.

\section{ВыВОДы}

Широко применяемые сегодня для изучения механизмов распространения и путей лечения различных заболеваний методы биолюминесцентного имиджинга обладают рядом неоспоримых достоинств по сравнению с остальными, главным из которых является сверхвысокая чувствительность. Однако недостатком всех используемых люминесцентных систем является необходимость добавления субстрата (люциферина) извне для проведения анализа. Разработка автономной люминесцентной системы эукариот на основе кассеты генов биолюминесцентной системы высших грибов является перспективным возможным решением этой проблемы.

\section{Литература}

1. Shimomura O. Bioluminescence: chemical principles and methods. Rev.ed. Singapore: World Scientific; 2012.

2. Kaskova ZM, Tsarkova AS, Yampolsky IV. 1001 lights: luciferins, luciferases, their mechanisms of action and applications in chemical analysis, biology and medicine. Chem Soc Rev. 2016; 45 (21): 6048-77. DOI: 10.1039/c6cs00296j.

3. Kiyama M, Saito R, Iwano S, Obata R, Niwa H, A Maki S. Multicolor bioluminescence obtained using firefly luciferin. Curr Top Med Chem. 2016; 16 (24): 2648-55.

4. Hirano T. Molecular origin of color variation in firefly (beetle) bioluminescence: A chemical basis for biological imaging. Curr Top Med Chem. 2016; 16 (24): 2638-47.

5. Nakajim, Y, Ohmiya Y. Bioluminescence assays: multicolor luciferase assay, secreted luciferase assay and imaging luciferase assay. Expert Opin Drug Discov. 2010; 5 (9): 835-49. DOI: 10.1517/17460441.2010.506213.

6. Sun YQ, Liu J, Wang P, Zhang J, Guo W. D-Luciferin Analogues: a Multicolor Toolbox for Bioluminescence Imaging. Angew Chem Int Ed. 2012 Aug 20; 51 (34): 8428-30. DOI: 10.1002/ anie.201203565.

7. Guardigli M, Lundin A, Roda A. "Classical" Applications of Chemiluminescence and Bioluminescence. In: Roda A, editor Chemiluminescence and Bioluminescence: Past, Present and Future. Cambridge: Royal Society of Chemistry; 2010. p. 143-90.

8. Tran Q, Lee H, Park J, Kim SH, Park J. Targeting cancer metabolism-revisiting the Warburg effects. Toxicol Res. $2016 \mathrm{Jul}$; 32 (3): 177-93. DOI: 10.5487/TR.2016.32.3.177.

9. Sattler UG, Meyer SS, Quennet V, Hoerner C, Knoerzer H, Fabian $\mathrm{C}$ et al. Glycolytic metabolism and tumour response to fractionated irradiation. Radiother Oncol. 2010 Jan; 94 (1): 102-9. DOI: 10.1016/j.radonc.2009.11.007.

10. Broggini-Tenzer A, Vuong V, Pruschy M. Metabolism of tumors under treatment: mapping of metabolites with quantitative bioluminescence. Radiother Oncol. 2011 Jun; 99 (3): 398-403. DOI: 10.1016/j.radonc.2011.05.041.

11. Slavine NV, McColl RW. Semi-automated Image Processing for Preclinical Bioluminescent Imaging. J Appl Bioinforma Comput Biol. 2015; 4 (1). pii: 114. DOI: 10.4172/2329-9533.1000114.

12. England CG, Ehlerding EB, Cai W. NanoLuc: a small luciferase is brightening up the field of bioluminescence. Bioconj

Chem. 2016 May 18; 27 (5): 1175-87. DOI: 10.1021/acs. bioconjchem.6b00112.

13. Schaub FX, Reza MS, Flaveny CA, Li W, Musicant AM, Hoxha S et al. Fluorophore-NanoLuc BRET reporters enable sensitive in vivo optical imaging and flow cytometry for monitoring tumorigenesis. Cancer Res. 2015 Dec 1; 75 (23): 5023-33. DOI: 10.1158/00085472.CAN-14-3538.

14. Kamkaew A, Sun H, England CG, Cheng L, Liu Z, Cai W. Quantum dot-NanoLuc bioluminescence resonance energy transfer enables tumor imaging and lymph node mapping in vivo. Chem Commun. 2016 May 19; 52 (43): 6997-7000. DOl: 10.1039/c6cc02764d.

15. Hsu CY, Chen CW, Yu HP, Lin YF, Lai PS. Bioluminescence resonance energy transfer using luciferase-immobilized quantum dots for self-illuminated photodynamic therapy. Biomaterials. 2013 Jan; 34 (4): 1204-12. DOI: 10.1016/j.biomaterials.2012.0844.

16. Kim YR, Kim S, Choi JW, Choi SY, Lee SH, Kim H et al. Bioluminescence-activated deep-tissue photodynamic therapy of cancer. Theranostics 2015; 5(8): 805.

17. Gupta RK, Patterson SS, Ripp S, Simpson ML, Sayler GS. Expression of the Photorhabdus luminescens lux genes (luxA, B, C, D, and E) in Saccharomyces cerevisiae. FEMS Yeast Res. 2003 Dec; 4 (3): 305-13.

18. Close DM, Patterson SS, Ripp S, Baek SJ, Sanseverino J, Sayler GS. Autonomous bioluminescent expression of the bacterial luciferase gene cassette (lux) in a mammalian cell line. PloS one. 2010; 5(8): e12441.

19. Purtov KV, Petushkov VN, Baranov MS, Mineev KS, Rodionova NS, Kaskova ZM et al. The chemical basis of fungal bioluminescence. Angew Chem Int Ed Engl. 2015 Jul 6; 54 (28): 8124-8. DOI: 10.1002/anie.201501779.

20. Kaskova ZM, Dörr FA, Petushkov VN, Purtov KV, Tsarkova AS, Rodionova NS et al. Mechanism and color modulation of fungal bioluminescence. Sci Adv. 2017 Apr 26; 3 (4): e1602847. DOI: 10.1126/sciadv. 1602847

21. Oba Y, Suzuki $Y$, Martins GN, Carvalho, RP, Pereira TA, Waldenmaier $\mathrm{HE}$ et al. Identification of hispidin as a bioluminescent active compound and its recycling biosynthesis in the luminous fungal fruiting body. Photochem Photobiol Sci. 2017 Sep 13; 16 (9): 1435-40. DOI: 10.1039/c7pp00216e. 
22. Berner M, Krug D, Bihlmaier C, Vente A, Müller R, Bechthold A Genes and enzymes involved in caffeic acid biosynthesis in the actinomycete Saccharothrix espanaensis. J Bacteriol. 2006 Apr; 188 (7): 2666-73. DOI: 10.1128/JB.188.7.2666-2673.2006.

\section{References}

1. Shimomura O. Bioluminescence: chemical principles and methods. Rev.ed. Singapore: World Scientific; 2012.

2. Kaskova ZM, Tsarkova AS, Yampolsky IV. 1001 lights: luciferins, luciferases, their mechanisms of action and applications in chemical analysis, biology and medicine. Chem Soc Rev. 2016 45 (21): 6048-77. DOI: 10.1039/c6cs00296j.

3. Kiyama M, Saito R, Iwano S, Obata R, Niwa H, A Maki S. Multicolor bioluminescence obtained using firefly luciferin. Curr Top Med Chem. 2016; 16 (24): 2648-55.

4. Hirano T. Molecular origin of color variation in firefly (beetle) bioluminescence: A chemical basis for biological imaging. Curr Top Med Chem. 2016; 16 (24): 2638-47.

5. Nakajim, Y, Ohmiya Y. Bioluminescence assays: multicolor luciferase assay, secreted luciferase assay and imaging luciferase assay. Expert Opin Drug Discov. 2010; 5 (9): 835-49. DOl: 10.1517/17460441.2010.506213.

6. Sun YQ, Liu J, Wang P, Zhang J, Guo W. D-Luciferin Analogues: a Multicolor Toolbox for Bioluminescence Imaging. Angew Chem Int Ed. 2012 Aug 20; 51 (34): 8428-30. DOI: 10.1002/ anie.201203565

7. Guardigli M, Lundin A, Roda A. "Classical" Applications of Chemiluminescence and Bioluminescence. In: Roda A, editor. Chemiluminescence and Bioluminescence: Past, Present and Future. Cambridge: Royal Society of Chemistry; 2010. p. 143-90.

8. Tran Q, Lee H, Park J, Kim SH, Park J. Targeting cancer metabolism-revisiting the Warburg effects. Toxicol Res. $2016 \mathrm{Jul}$; 32 (3): 177-93. DOI: 10.5487/TR.2016.32.3.177.

9. Sattler UG, Meyer SS, Quennet V, Hoerner C, Knoerzer H, Fabian $\mathrm{C}$ et al. Glycolytic metabolism and tumour response to fractionated irradiation. Radiother Oncol. 2010 Jan; 94 (1): 102-9. DOI: 10.1016/j.radonc.2009.11.007.

10. Broggini-Tenzer A, Vuong V, Pruschy M. Metabolism of tumors under treatment: mapping of metabolites with quantitative bioluminescence. Radiother Oncol. 2011 Jun; 99 (3): 398-403. DOI: 10.1016/j.radonc.2011.05.041.

11. Slavine NV, McColl RW. Semi-automated Image Processing for Preclinical Bioluminescent Imaging. J Appl Bioinforma Comput Biol. 2015; 4 (1). pii: 114. DOI: 10.4172/2329-9533.1000114.

12. England CG, Ehlerding EB, Cai W. NanoLuc: a small luciferase is brightening up the field of bioluminescence. Biocon Chem. 2016 May 18; 27 (5): 1175-87. DOI: 10.1021/acs. bioconjchem.6b00112.
13. Schaub FX, Reza MS, Flaveny CA, Li W, Musicant AM, Hoxha S et al. Fluorophore-NanoLuc BRET reporters enable sensitive in vivo optical imaging and flow cytometry for monitoring tumorigenesis. Cancer Res. 2015 Dec 1; 75 (23): 5023-33. DOl: 10.1158/00085472.CAN-14-3538

14. Kamkaew A, Sun $H$, England CG, Cheng L, Liu Z, Cai W. Quantum dot-NanoLuc bioluminescence resonance energy transfer enables tumor imaging and lymph node mapping in vivo. Chem Commun. 2016 May 19; 52 (43): 6997-7000. DOI: 10.1039/c6cc02764d.

15. Hsu CY, Chen CW, Yu HP, Lin YF, Lai PS. Bioluminescence resonance energy transfer using luciferase-immobilized quantum dots for self-illuminated photodynamic therapy. Biomaterials. 2013 Jan; 34 (4): 1204-12. DOI: 10.1016/j.biomaterials.2012.0844.

16. Kim YR, Kim S, Choi JW, Choi SY, Lee SH, Kim H et al. Bioluminescence-activated deep-tissue photodynamic therapy of cancer. Theranostics 2015; 5(8): 805.

17. Gupta RK, Patterson SS, Ripp S, Simpson ML, Sayler GS Expression of the Photorhabdus luminescens lux genes (luxA, B, C, D, and E) in Saccharomyces cerevisiae. FEMS Yeast Res. 2003 Dec; 4 (3): 305-13.

18. Close DM, Patterson SS, Ripp S, Baek SJ, Sanseverino J, Sayler GS. Autonomous bioluminescent expression of the bacterial luciferase gene cassette (lux) in a mammalian cell line. PloS one. 2010; 5(8): e12441.

19. Purtov KV, Petushkov VN, Baranov MS, Mineev KS, Rodionova NS, Kaskova ZM et al. The chemical basis of fungal bioluminescence. Angew Chem Int Ed Engl. 2015 Jul 6; 54 (28): 8124-8. DOI: 10.1002/anie.201501779.

20. Kaskova ZM, Dörr FA, Petushkov VN, Purtov KV, Tsarkova AS, Rodionova NS et al. Mechanism and color modulation of fungal bioluminescence. Sci Adv. 2017 Apr 26; 3 (4): e1602847. DOl: 10.1126/sciadv.1602847.

21. Oba $Y$, Suzuki $Y$, Martins GN, Carvalho, RP, Pereira TA, Waldenmaier $\mathrm{HE}$ et al. Identification of hispidin as a bioluminescent active compound and its recycling biosynthesis in the luminous fungal fruiting body. Photochem Photobiol Sci. 2017 Sep 13; 16 (9): 1435-40. DOl: 10.1039/c7pp00216e.

22. Berner M, Krug D, Bihlmaier C, Vente A, Müller R, Bechthold A. Genes and enzymes involved in caffeic acid biosynthesis in the actinomycete Saccharothrix espanaensis. J Bacteriol. 2006 Apr; 188 (7): 2666-73. DOI: 10.1128/JB.188.7.2666-2673.2006. 